\title{
AMELIORATIVE EFFECT OF PSIDIUM GUAJAVA LEAF EXTRACT ON PARAQUAT INDUCED RENAL AND REPRODUCTIVE HORMONE TOXICITY
}

\author{
OKORONDU, M.M.O. ${ }^{1}$, OKORONDU, S.I ${ }^{2}$., ALISI, C.S ${ }^{1}$., EMEJULU, A.A ${ }^{1}$, \\ ${ }^{1}$ Department of Biochemistry, Federal University of Technology Owerri, Nigeria. \\ ${ }^{2}$ Department of Microbiology, Federal University of Technology Owerri, Nigeria. \\ DOI: $10.31364 / S C I R J / v 7 . i 4.2019 . P 0419633$ \\ http://dx.doi.org/10.31364/SCIRJ/v7.i4.2019.P0419633
}

\begin{abstract}
Ameliorative effect of Psidium guajava (PG) leaf extract on Paraquat (PQ) induced Renal and Reproductive Hormone toxicity in rats were investigated. Thirty healthy male wistar rats were used for the in vivo experiment. The rats were divided into five groups of six animals each. Extract was administered daily for thirty (30) days using normal saline. Animals received $3.5 \mathrm{mg} / \mathrm{kg}$ of PQ intraperitoneally on the $15^{\text {th }}$ day of the experiment. Electrolytes (sodium, potassium, and chloride), Urea and Creatinine concentrations were estimated to investigate the protective effects of PG on Kidney functions. White Blood Cell (total), Lymphocyte count, Neutrophil count, and Platelet count were equally estimated to investigate the protective effect of PG on immune system. Concentration of the reproductive hormones- Follicle Stimulating hormone (FSH), Leutinizing hormone (LH), Testosterone and prolactin were estimated to determine reproductive health. Histological study of the kidney was also carried out in order to find out the effectiveness of PG on renal functions. Results showed significant increase in Serum Sodium, Urea and Creatinine concentrations, WBC-T, and lymphocytes following PQ exposure at $(\mathrm{p}<0.05)$. There was also a significant decrease of Neutrophils, Testosterone, FSH, after PQ exposure at $(\mathrm{P}<0.05)$. Histological result of the kidney showed moderate cellular activity close to that of the normal and the Cyto-architecture was protected. PG leaf extract significantly improved and ameliorated changes in paraquat induced renal and reproductive hormone toxicity and hence may be recommended for the treatment of paraquat induced renal and hormonal toxicity especially in accidental or occupational exposures of the chemical.
\end{abstract}

Keywords: Paraquat, Psidium guajava, Ethanol extract, Renal and Hormonal toxicity.

\section{INTRODUCTION}

Paraquat (PQ) belongs to a group of redox cycling compounds capable of inducing mitochondrial damage, increases reactive oxygen species (ROS) production and causes oxidative stress (Casteilo et al, 2007). It is a toxic chemical widely used as a herbicide (plant killer) primarily for weed and grass control. Despite the fact that it has been banned in so many countries, some elements of it are still seen in and around us especially in the Agro chemical industries. Approximately $70 \%$ of the Nigerian population engages in agricultural production at a subsistence level and about $50 \%$ of the said population that engage in large scale farming makes use of herbicides for better productivity and low cost. Herbicides such as paraquat poses a great threat to such farmers who comes in contact with it through various ways such as inhalation, oral or even dermal contact. Its mode of action in weeds is that it interferes with electron transfer, it is an electron acceptor in redox and radical reactions. It accepts electron from photosystem1, transfers them to molecular oxygen and by so doing, destructive reactive oxygen species are produced. Its mode of action in animals and humans is that it causes extensive damage to the mitochondria of cells through the production of free radicals and oxidative stress, resulting in the interruption of important biochemical processes, cell death, and multi organ failure (Suntress 2002, Cocheme et al, 2009), and the organs mostly affected are the lungs, liver and kidney. Alterations in the renal and reproductive hormone parameters could be used as biomarker for paraquat renal and hormonal toxicity. 
Psidium Guajava, commonly known as Guava is widely cultivated in tropical and subtropical regions around the world. Native tribesmen have used Psidium guajava for a lot of medicinal purposes thousands of years before modern medicine documented the specific chemical compounds in the tropical fruit. Traditionally, the leaves were brewed to treat intestinal tract problems or ground into a poultice and applied to the skin to treat open wounds and rashes. Both the unripe and ripe fruits have been consumed to suit stomach upset and when the flesh is ready to eat, it acts as a mild laxative and the unripe fruit works as an antidiarrheal (Joseph et al,2011). Some recent studies have shown that certain extracts from the leaves and bark can act as an anti-inflammatory, prevent bacterial growth, and in some cases inhibit the spread of cancer (Manosroi et al, 2006). Guava is an excellent antioxidant and a good source of Vitamin C.

This study therefore is to assess the ameliorative effect of ethanol extract of Psidium guajava on Paraquat induced Renal and Reproductive Hormone toxicity.

\section{MATERIALS AND METHODS}

\section{Plant Materials}

Matured leaves of Psidium guajava freshly harvested were obtained from Umuagu, Umuguma in Owerri west Local Government Area of Imo State. The leaves were authenticated by Dr. Cyriacus Udah, former Director of Forestry, Imo State Ministry of Environment.

\section{Safety study of Psidium guajava and dose administration:}

Safety study of P.G and dose administration was according to Sarmistha et al, 2010): Acute oral toxicity test for the ethanolic extract of leaves of P.G was carried out as per (OECD guidelines 425 ). Two arbitrary doses of $250 \mathrm{mg} / \mathrm{kg}$ b.wt and $500 \mathrm{mg} / \mathrm{kg}$ b.wt were selected for the study, as the extract was found to be safe even at doses more than $5000 \mathrm{mg} / \mathrm{kg} \mathrm{b}$.wt without any sign of toxicity or mortality.

\section{Animals}

Thirty healthy male albino rats weighing between 72-113gm were obtained from the Department of Zoology and Environmental Biology, University of Nigeria Nsukka. The rats were acclimatized for two weeks before the commencement of the experiment. The rats were provided with their respective diets along with portable drinking water ad libitum throughout the experimental period. The rats were housed in cages under standard laboratory conditions. All experiments were carried out as approved by appropriate ethics committee (SOBS-BCH-EC) and all the animals received proper human care in accordance with the guidelines for ethical treatment of laboratory animals provided by the National Institute of Health, USA. The Animals were being weighed weekly, and their weights recorded.

\section{Methods}

\section{Preparation of Plant Extract}

The leaves of P.guajava were air dried at room temperature for one week to a constant weight. The dried leaves were ground to fine powder using a mill (BL-335Kenwood) and stored in air tight container. 400g of the powdered leaves were soaked in $2.0 \mathrm{~L}, 70 \%$ ethanol. The whole set up was left to stand for 4 days with occasional agitation. They were filtered through a qualitative filter paper (no 1: Whatman, England). The crude leaf solution was rotor evaporated at $49^{\circ} \mathrm{C}$ (Buchi Rotavapour, Japan) and the extract was obtained. The extract was finally stored in the refrigerator throughout the experimental period and was prepared daily for administration.

\section{Experimental Design}

The rats were divided into five groups of six animals each after two weeks of acclimatization. The plant extract was given at 3 different doses for 30 days.

Group 1: normal control group and received normal saline, food and water.

Group 2: intoxicated control and received only paraquat, food and water. 
Group 3: $1^{\text {st }}$ treated group and received paraquat with $200 \mathrm{mg} / \mathrm{kg}$ b.wt body weight of P.G extract with food and water.

Group 4: $2^{\text {nd }}$ treated group and received paraquat with $400 \mathrm{mg} / \mathrm{kg}$ b.wt body weight of P.G extract with food and water.

Group 5: $3^{\text {rd }}$ treated group and received paraquat with $800 \mathrm{mg} / \mathrm{kg}$ b.wt body weight of P.G extract with food and water.

Toxicity was induced with $3.5 \mathrm{mg} / \mathrm{kg}$ b.wt of paraquat by I.P injection on the $15^{\text {th }}$ day of the experiment and antioxidant activity measured on the $30^{\text {th }}$ day. Blood sample were collected by optical puncture using orbital technique for assay of biochemical parameters. Animals were anaesthetized and the liver was perfused and preserved with formal saline for histological studies.

\section{ASSAY OF BIOCHEMICAL PARAMETERS}

Urea concentration was determined according to the method described by Searcy et al. (1967). Urea is hydrolyzed by the action of the urease to produce ammonia and carbon dioxide. The ammonia reacts with hypochlorite and phenol in the presence of nitroprusside to form indophenol, which in alkaline medium gives an intense blue colour. The intensity of the colour formed is directly proportional to concentration of urea in the sample. The Creatinine concentration was determined based on the method described by Fabiny and Ertingshausen (1971). Creatinine in the sample reacted with picrate in alkaline medium forming a coloured complex and the complex formation rate was measured in a short period. The concentration of potassium was determined based on the method described by Terri and sesin (1958). The amount of potassium was determined by sodium tetraphenylboron in a specifically prepared mixture to produce colloidal suspension. The turbidity is proportional to potassium concentration. Chloride concentration was determined based on the method described by Skeggs and Hochestrasser (1964). Sodium Concentration was determined based on the modification of those first described by Maruna (1958) and Trinder (1951). Sodium was precipitated as the triple salt, sodium magnesium uranyl acetate, with the excess uranium being reacted with ferrocyanide, producing a chromophore whose absorbance varies inversely as the concentration of sodium in the sample. The full blood count was done with the sysmex K-21n automatic multi-parameter blood cell counter for in vitro diagnostic use in clinical laboratories. Counting of blood cells is based on the volumetric impedance method, directly measuring white blood cells (WBC), The instrument differentiates the subpopulations of lymphocytes, Specially formulated reagents cause the WBC membrane to shrink around the nucleus while keeping the cell intact, allowing separation of white cells according to their volume. Lymphocytes fall within the small-cell region, and neutrophils within the large-cell region. Follicle stimulating hormones was measured according to the method of Wennik et al (1990) and Odell et al,(1981). Here, the immobilization takes place during the assay at the surface of a microplate well through the interaction of streptavidin coated on the well and exogenously added biotinylated monoclonal anti-FSH antibody. Testosterone was measured according to the method of Tietz, (1995). Upon mixing biotinylated antibody, enzyme-antigen conjugate and a serum containing the native antigen, a competition reaction conjugate for a limited number of antibody binding site. Prolactin was measured according to the method of Wennink,et al,(1990) and Odell, et al, (1981). The immobilization takes place during the assay at the surface of a microplate well through the interaction of streptavidin coated on the well and exogenously added biotinylated monoclonal anti PRL antibody. Histological study was carried out with kidney samples from different groups. This was carried out to crosscheck the results that were obtained from the biochemical assays. The method described by Okoro (2002) was used with minor modifications.

\section{Statistical Analysis}

Data were analysed using appropriate software, Scientific package for Social Sciences (SPSS). Results were presented as mean \pm standard deviation of six observations for biochemical parameters and statistically analysed using one-way analysis of variance on statistical computer software program "Analyze it statistical software for Microsoft excel" (leeds U.K). The degree of statistical difference was accepted at $\mathrm{P}<0.05$.

\section{RESULTS AND DISCUSSION}

The results obtained are presented in Fig 1-13 respectively, it shows a significant $(\mathrm{P}<0.05)$ increase of serum Creatinine, serum Urea concentration, sodium concentrations, WBC-T, lymphocyte count, a significant $(\mathrm{P}<0.05)$ decrease of potassium concentration, 
Neutrophil count, a non significant decrease of platelet count, and a non significant $(\mathrm{P}<0.05)$ variation of chloride concentration after paraquat intoxication.

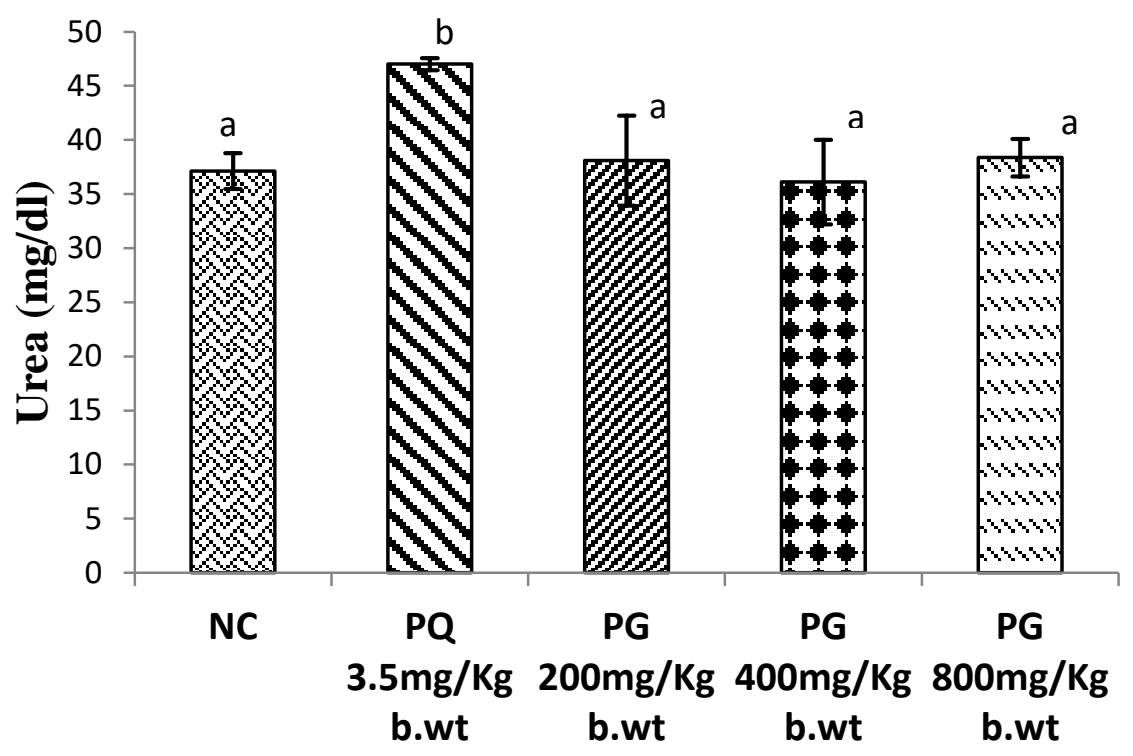

Fig 1: Effect of Psidium guajava leaf extract administration on serum Urea concentration of male wistar albino rats administered $3.5 \mathrm{mg} / \mathrm{kg}$ b.wt. Paraquat.

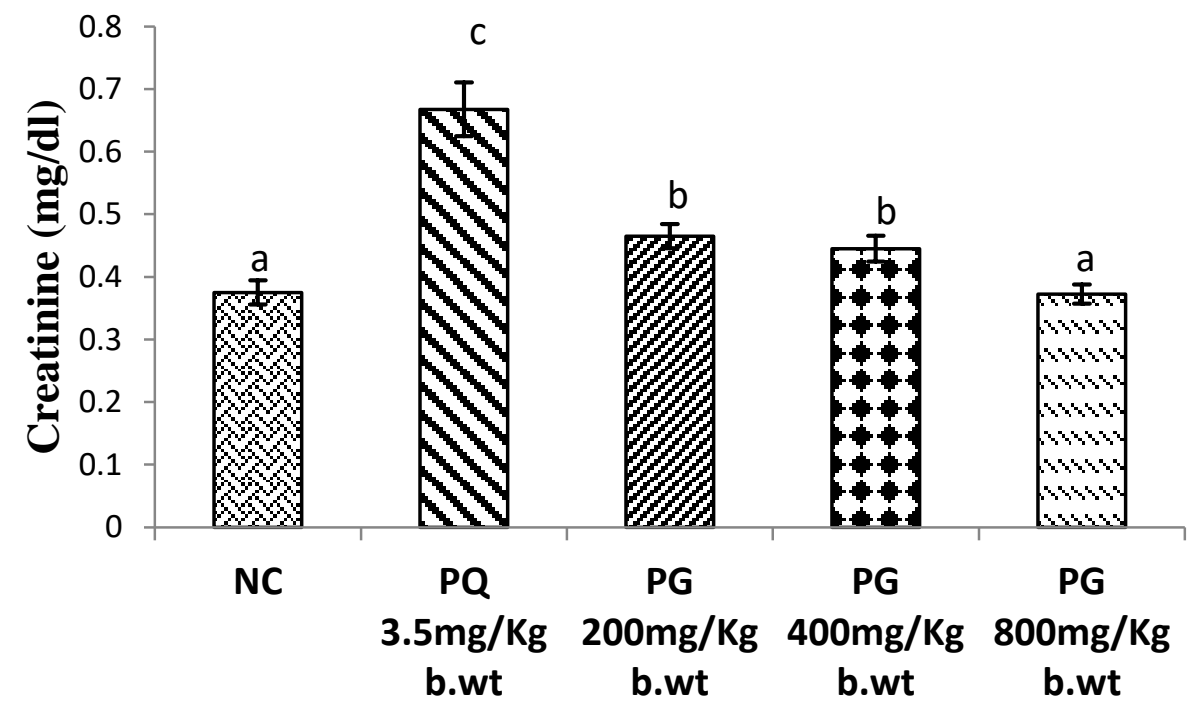

Fig2: Effect of Psidium guajava leaf extract administration on serum creatinine concentration of male wistar albino rats administered 3.5mg/kg b.wt. Paraquat. 


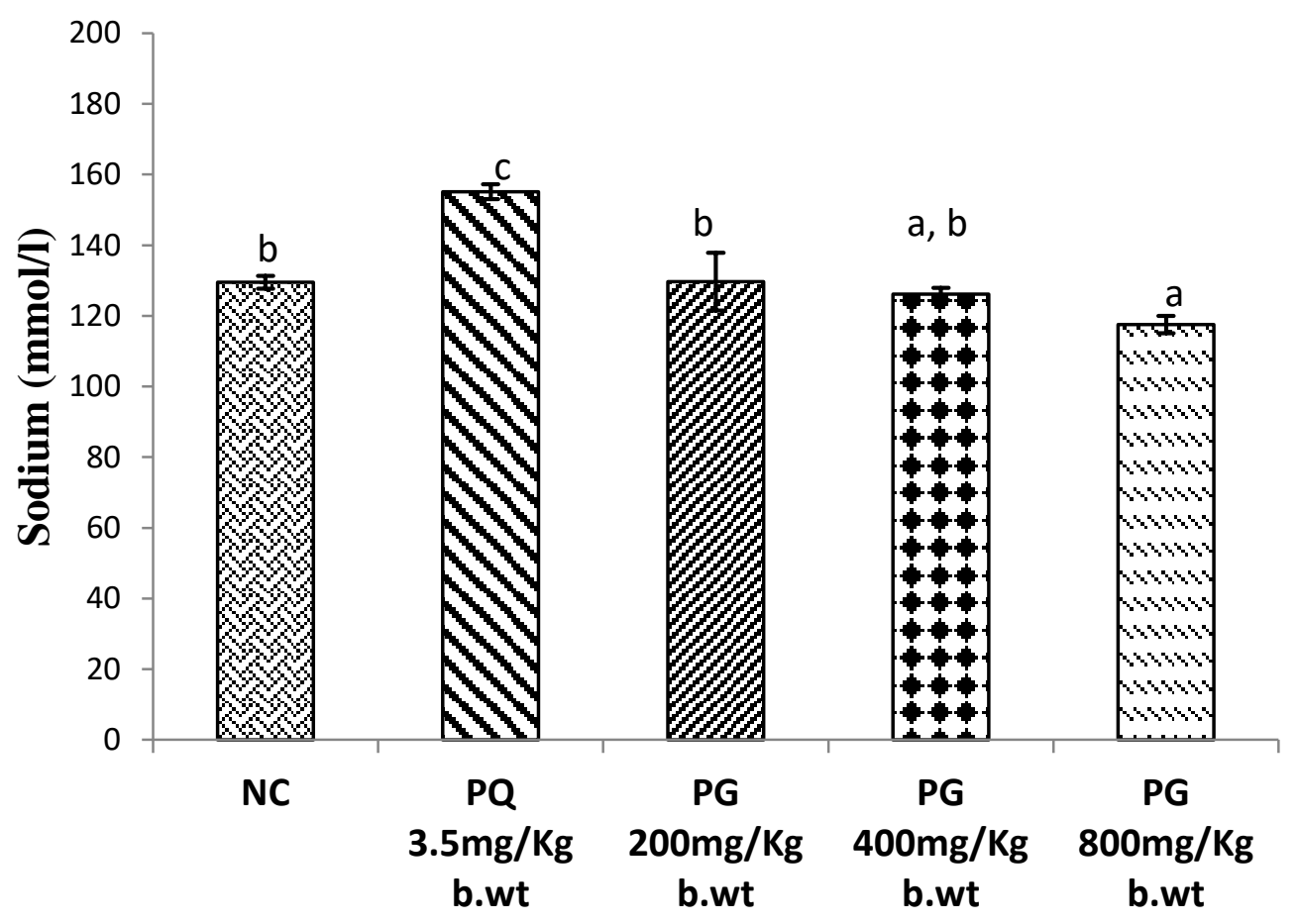

Fig3: Effect of Psidium guajava leaf extract administration on serum sodium concentration of male wistar albino rats administered 3.5mg/kg b.wt. Paraquat.

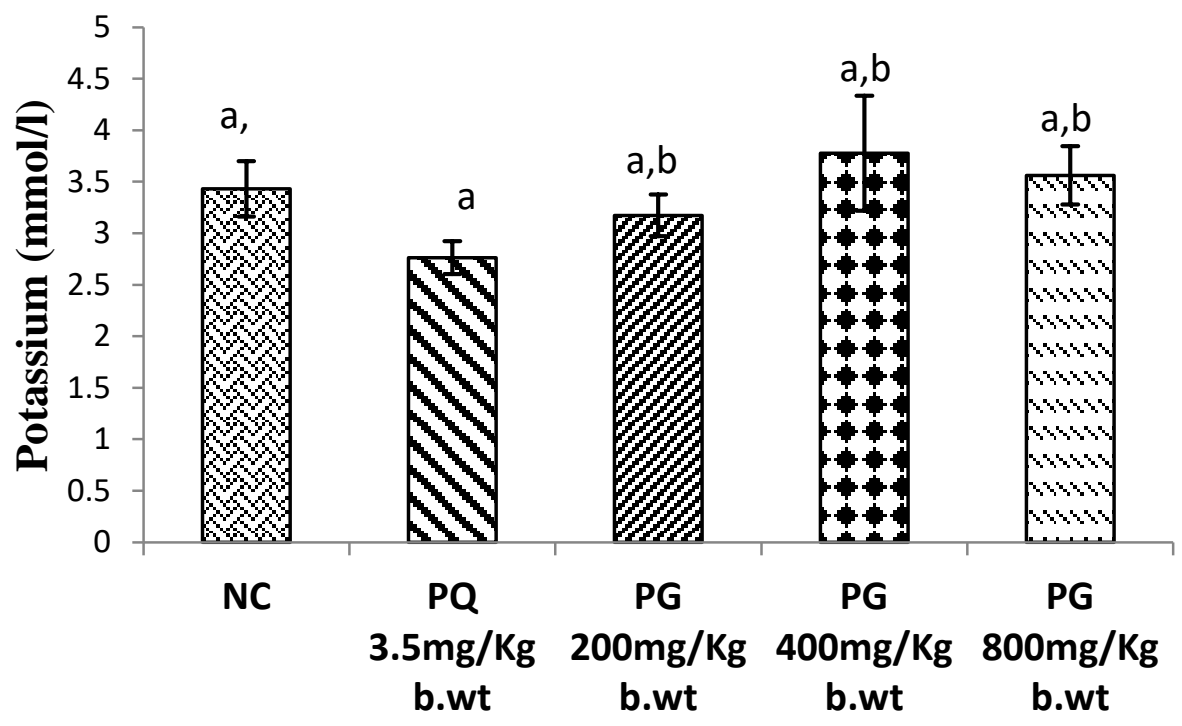

Fig4: Effect of Psidium guajava leaf extract administration on serum potassium concentration of male wistar albino rats administered 3.5mg/kg b.wt. Paraquat. 


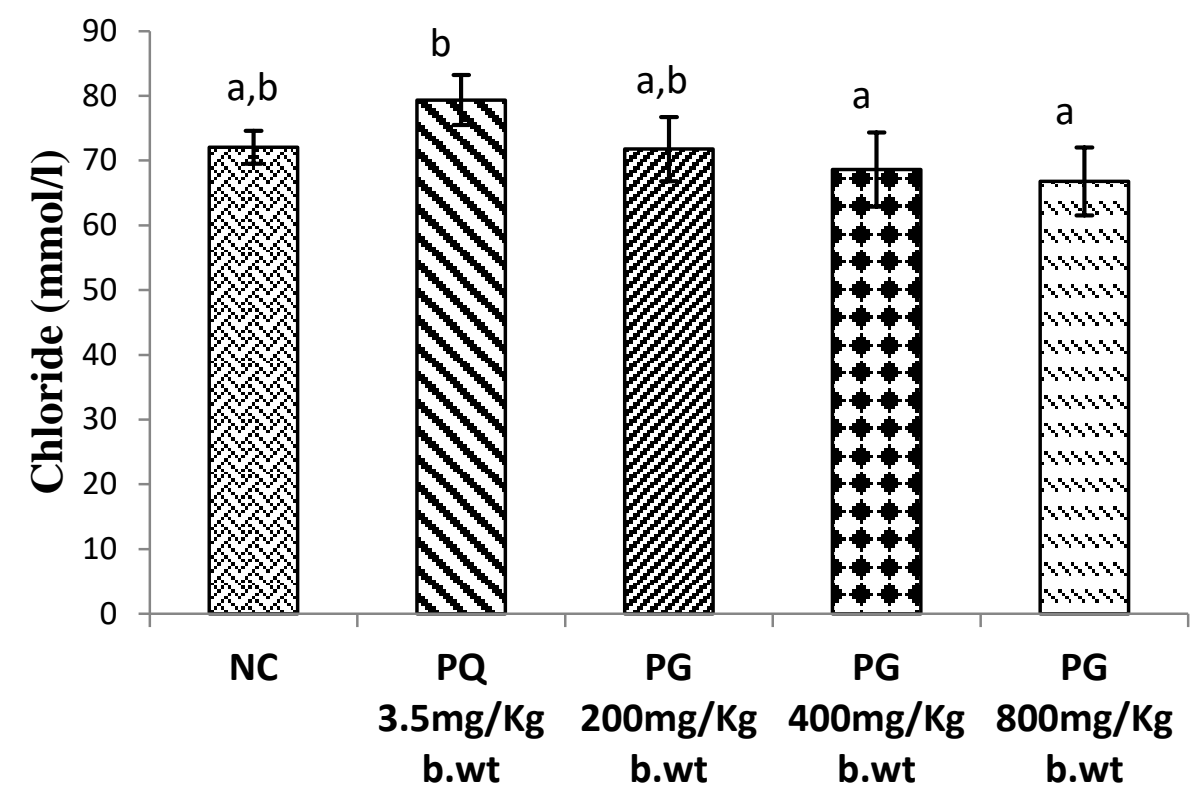

Fig5: Effect of Psidium guajava leaf extract administration on serum Chloride concentration of male wistar albino rats administered $3.5 \mathrm{mg} / \mathrm{kg}$ b.wt. Paraquat.

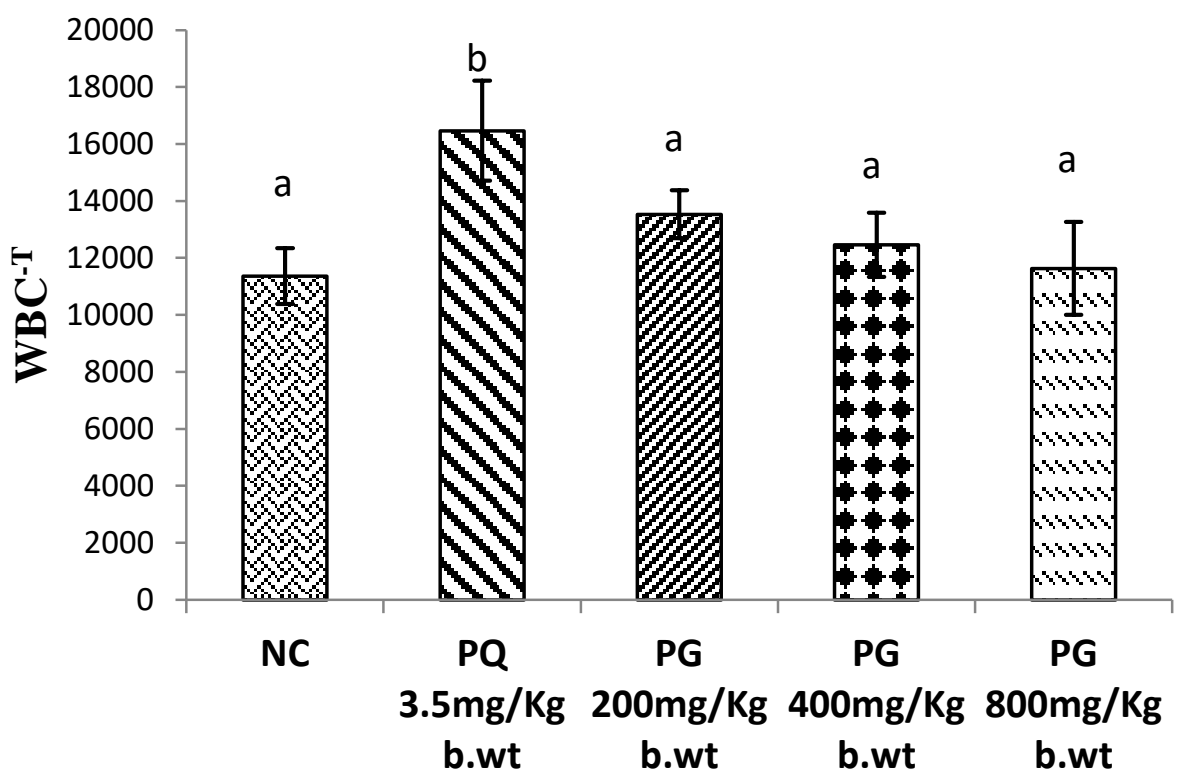

Fig6: Effect of Psidium guajava leaf extract administration on total white blood cells count of male wistar albino rats administered 3.5mg/kg b.wt. Paraquat. 


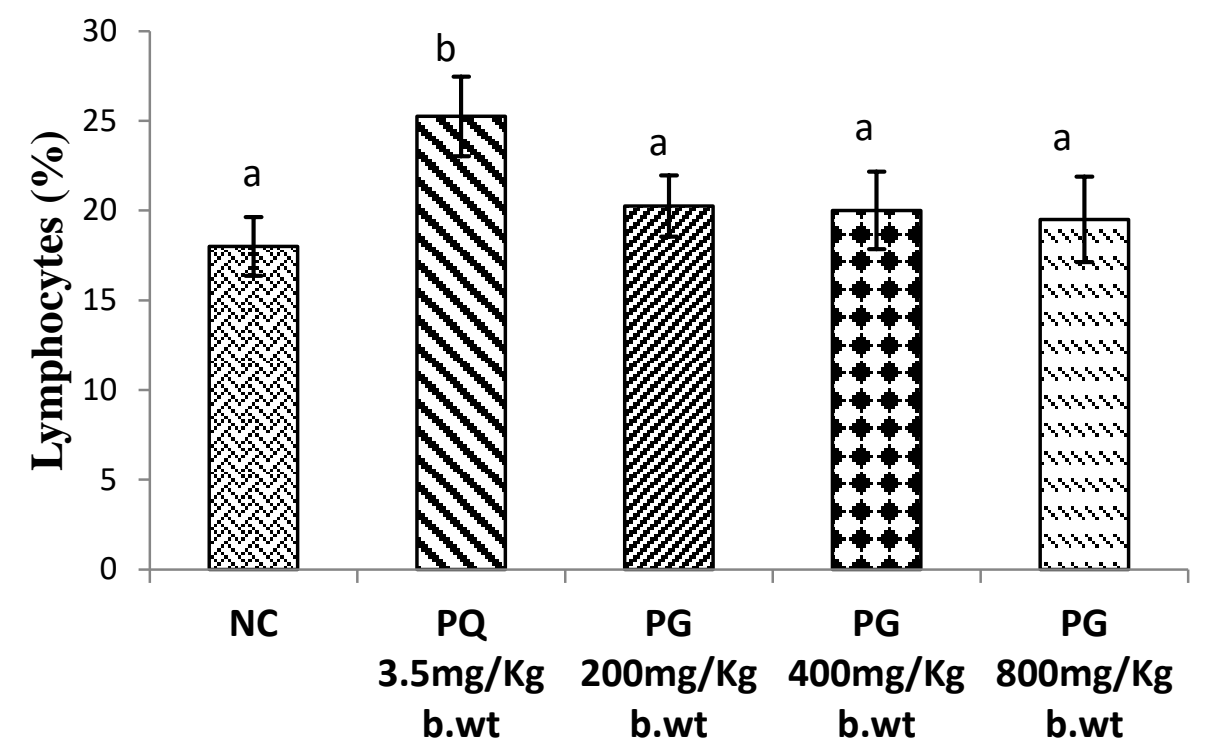

Fig7: Effect of Psidium guajava leaf extract administration on absolute Lymphocytes count of male wistar albino rats administered 3.5mg/kg b.wt. Paraquat.

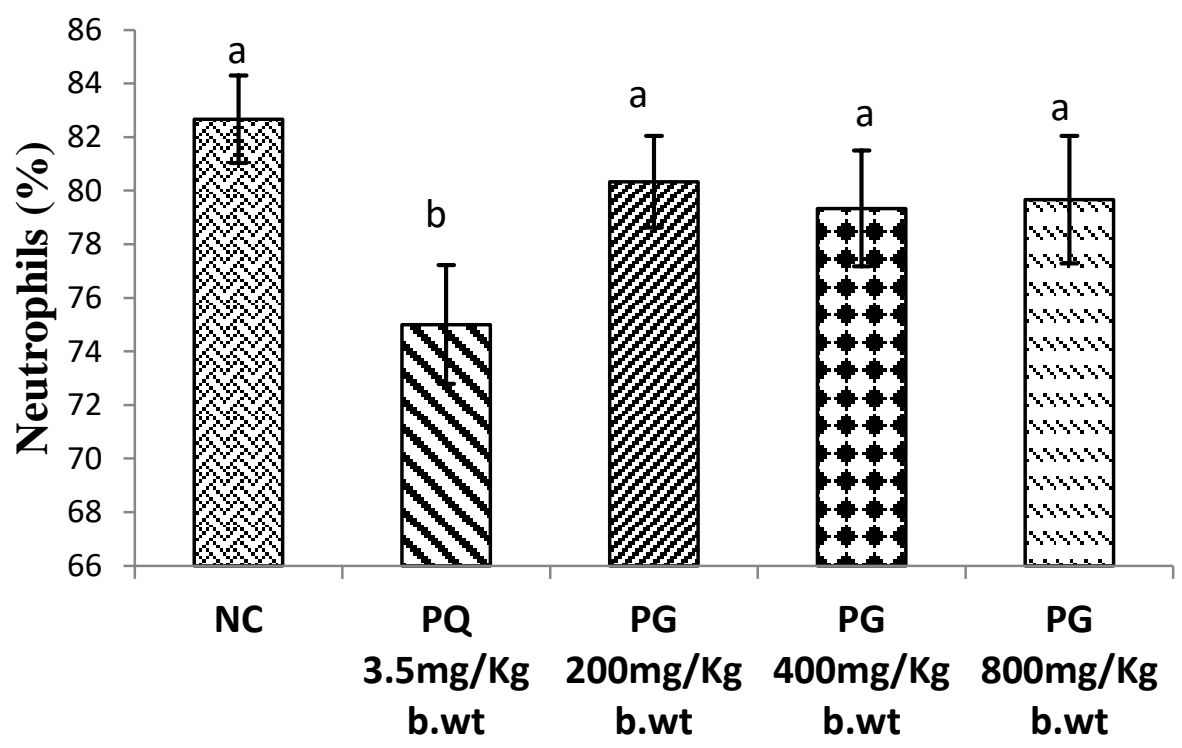

Fig8: Effect of Psidium guajava leaf extract administration on absolute Neutrophil count of male wistar albino rats administered 3.5mg/kg b.wt. Paraquat. 


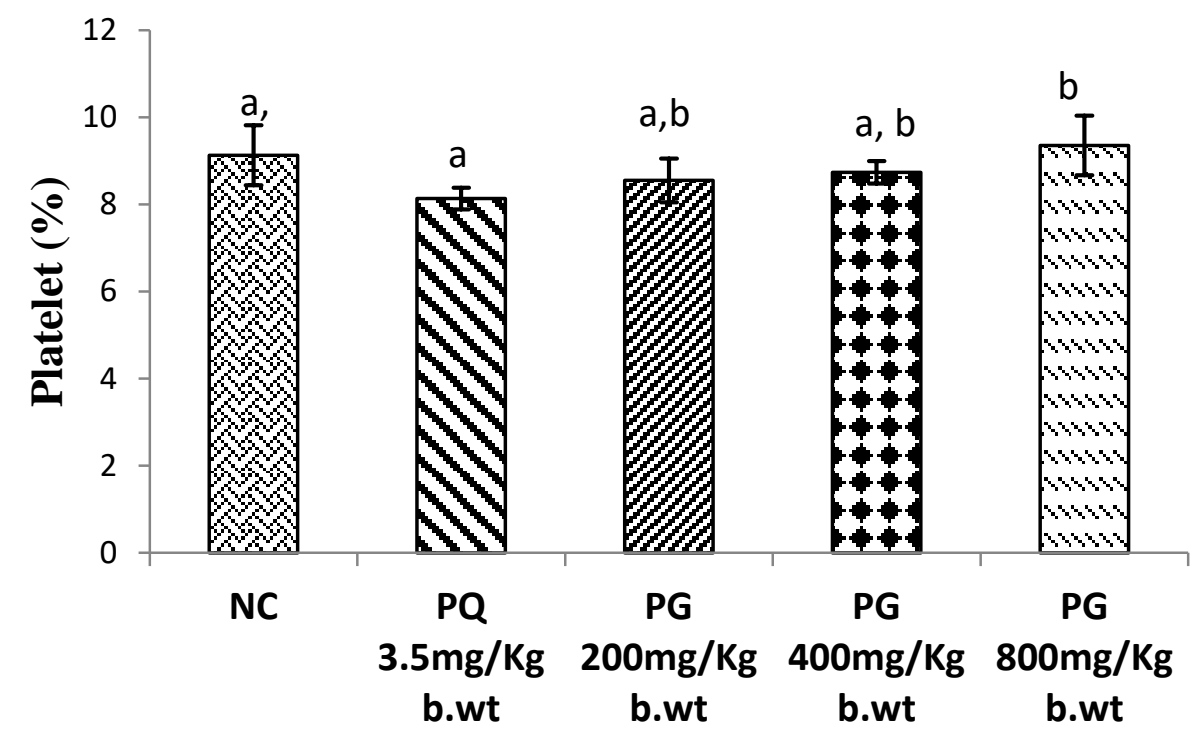

Fig9: Effect of Psidiumguajava leaf extract administration on platelet count of male wistar albino rats administered $3.5 \mathrm{mg} / \mathrm{kg}$ b.wt. Paraquat.

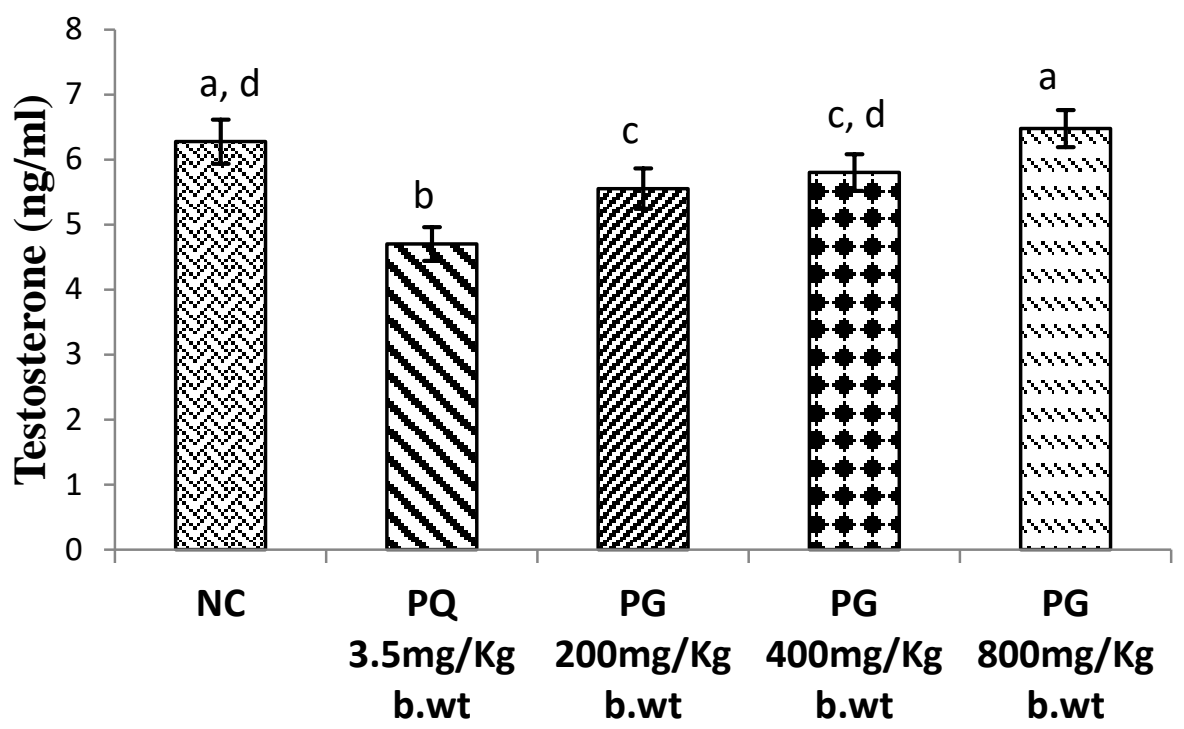

Fig10: Effect of Psidium guajava leaf extract administration on serum testosterone concentration of male wistar albino rats administered 3.5mg/kg b.wt. Paraquat. 


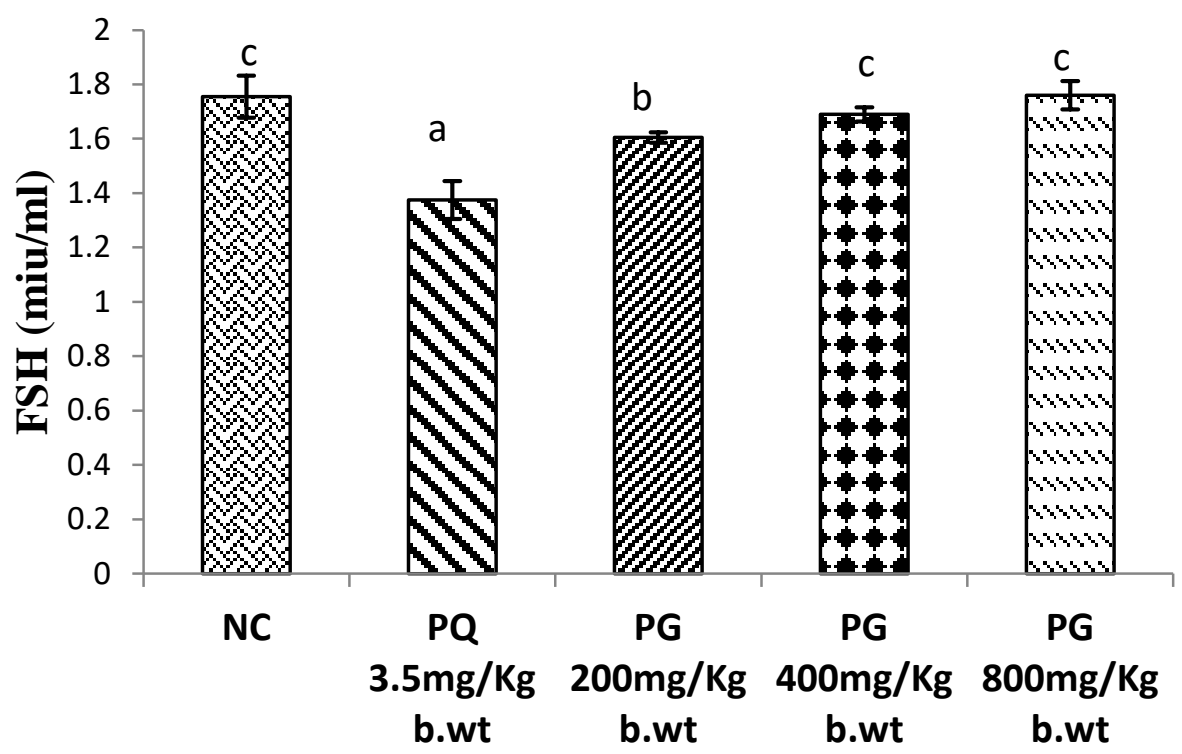

Fig11: Effect of Psidium guajava leaf extract administration on serum Follicle stimulating hormone concentration of male wistar albino rats administered $3.5 \mathrm{mg} / \mathrm{kg}$ b.wt. Paraquat.

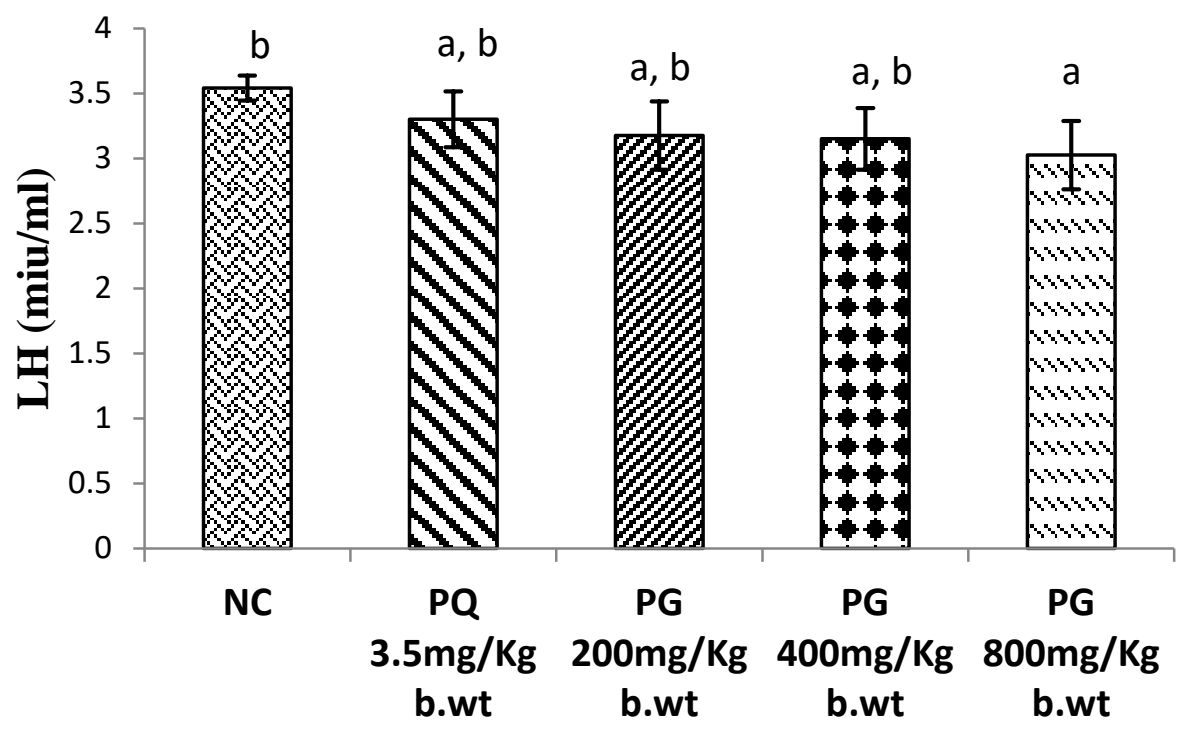

Fig12: Effect of Psidium guajava leaf extract administration on serum leuteinizing hormone concentration of male wistar albino rats administered 3.5mg/kg b.wt. Paraquat 


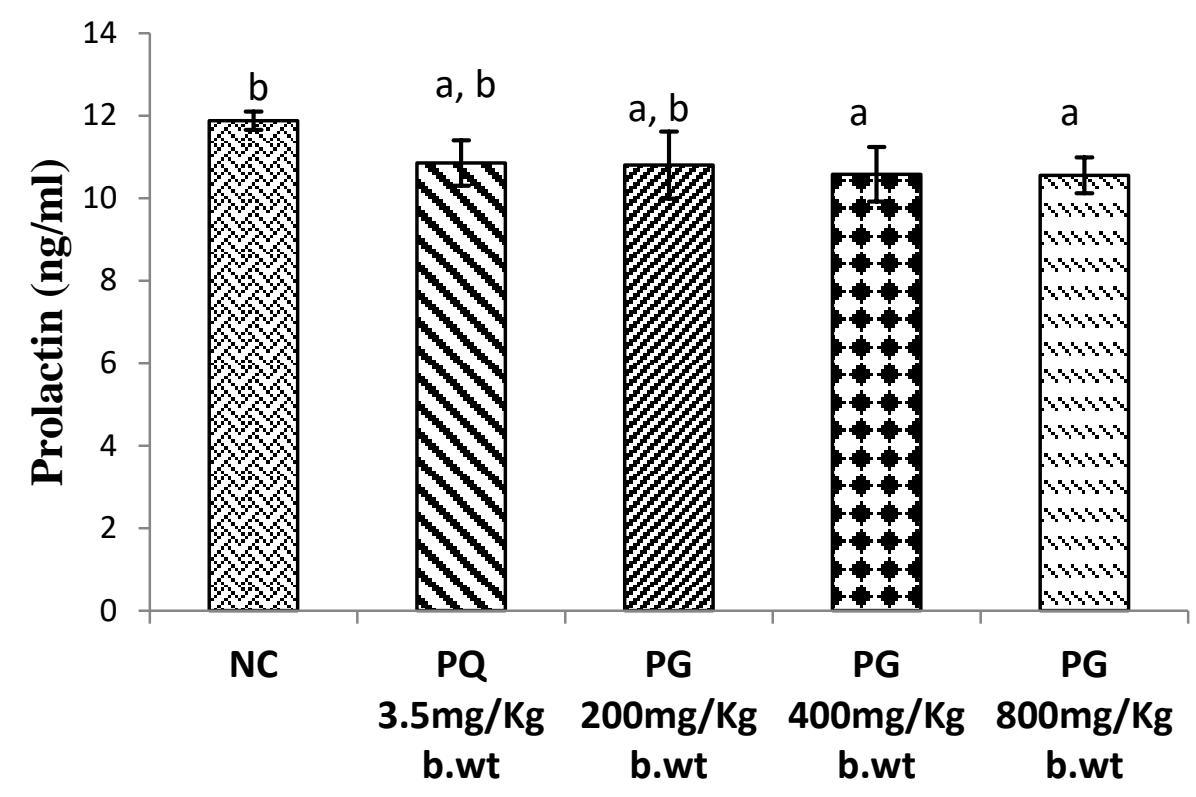

Fig13: Effect of Psidium guajava leaf extract administration on serum prolactin concentration of male wistar albino rats administered 3.5mg/kg b.wt. Paraquat.

The histological result of the kidney in plate 1(Normal Control) Shows a section typical of the kidney. The cortex is seen to be housing the tuft of the glomerulus with slightly loose basement membrane. The interstitium is stained red. The collecting tubules appear normal in architecture and no histopathological lesion was seen. Plate 2 (Paraquat intoxication, with no treatment) shows that there was necrosis in some of the proximal and distal convoluted tubules. The tuft of the glomerulus has a large loose basement membrane. Plate 3 (Paraquat intoxication, $+200 \mathrm{mg} / \mathrm{ml}$ guava extract treatment) showed necrosis mainly in the distal convoluted tubules. The tuft of the glomerulus has a much larger loose basement membrane. Plate 4 (Paraquat intoxication, $+400 \mathrm{mg} / \mathrm{ml}$ guava extract treatment) showed that the cell of the distal convoluted tubules was less necrotic. The urinary space was minimal, while Plate 5 (Paraquat intoxication, $+800 \mathrm{mg} / \mathrm{ml}$ guava extract treatment) showed moderate cellular activity close to that of the normal control. The Cyto-architecture was protected.

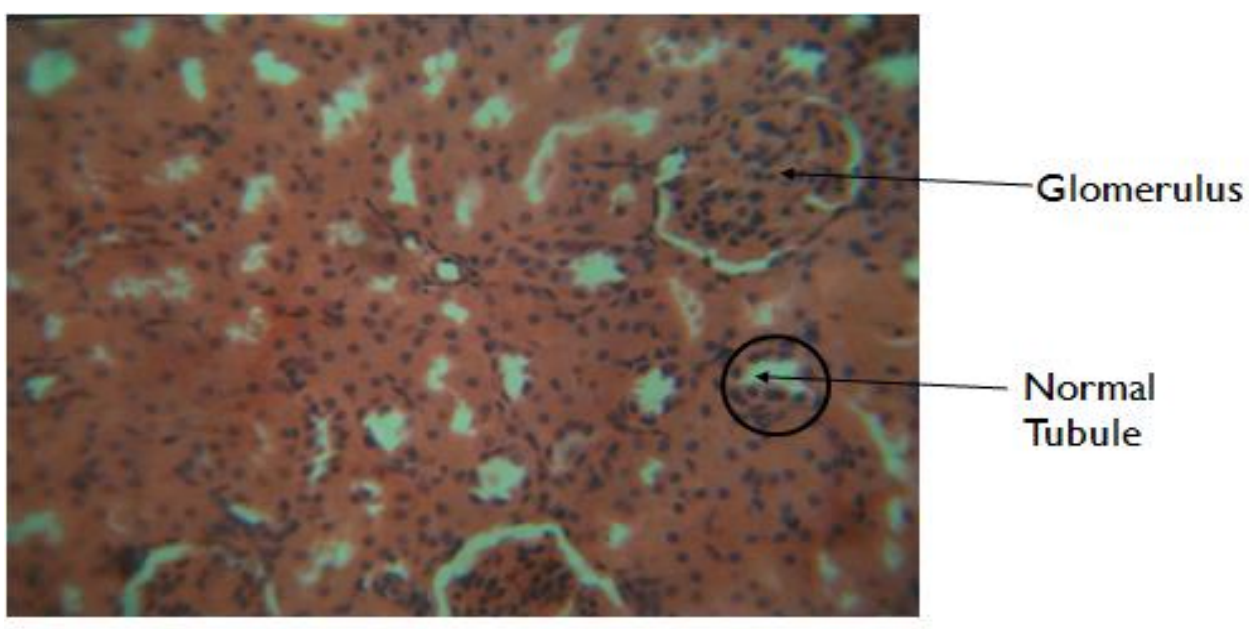

Plate 1 (Normal control group) 


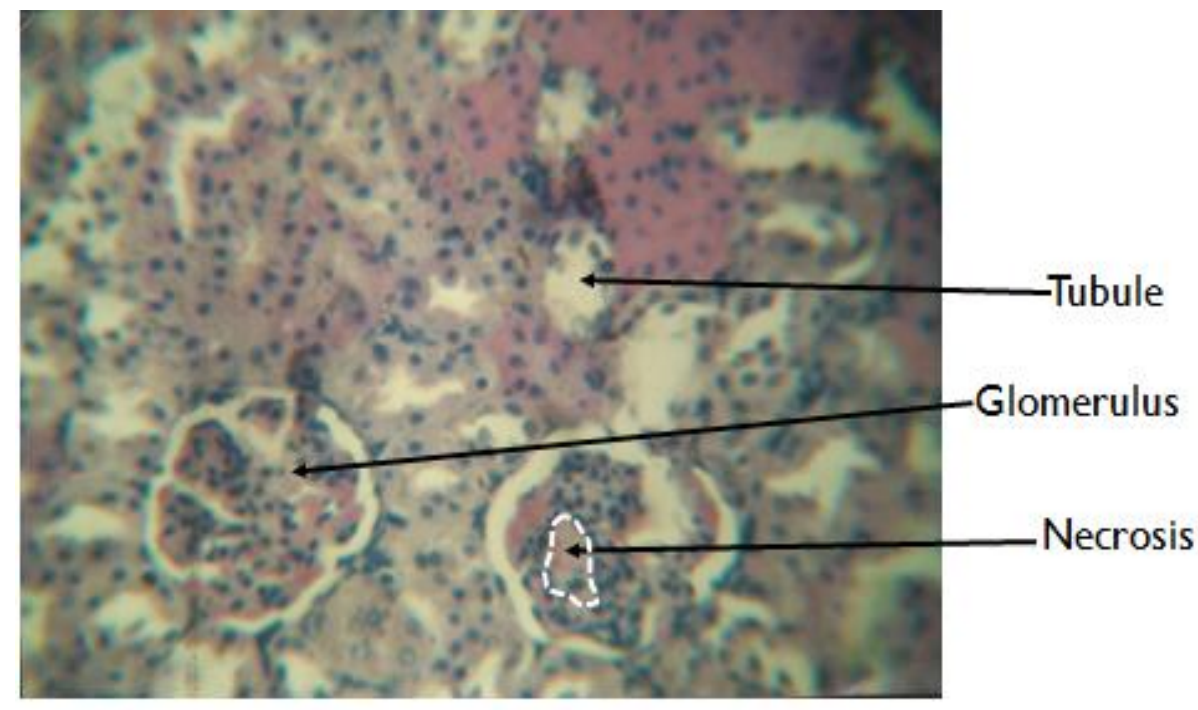

Plate 2 (Paraquat intoxication, with no treatment)

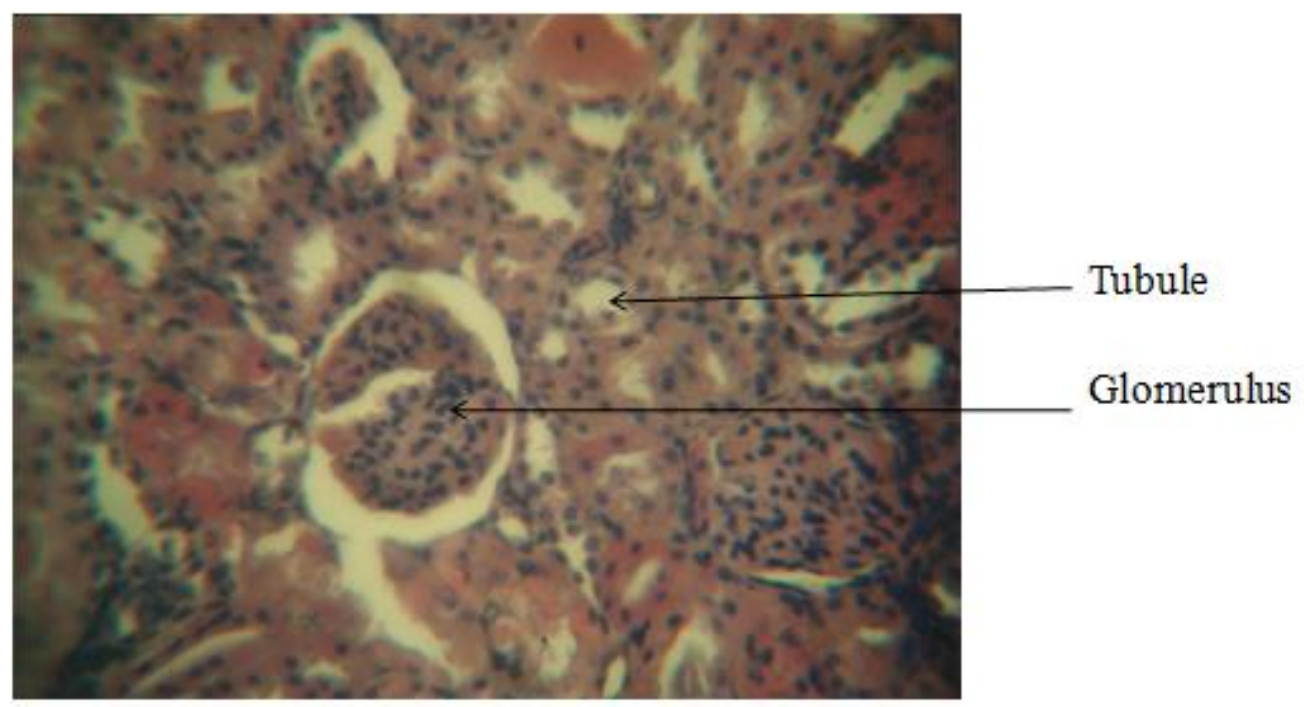

Plate 3 (Paraquat intoxication, $+200 \mathrm{mg} / \mathrm{ml}$ guava extract treatment): 


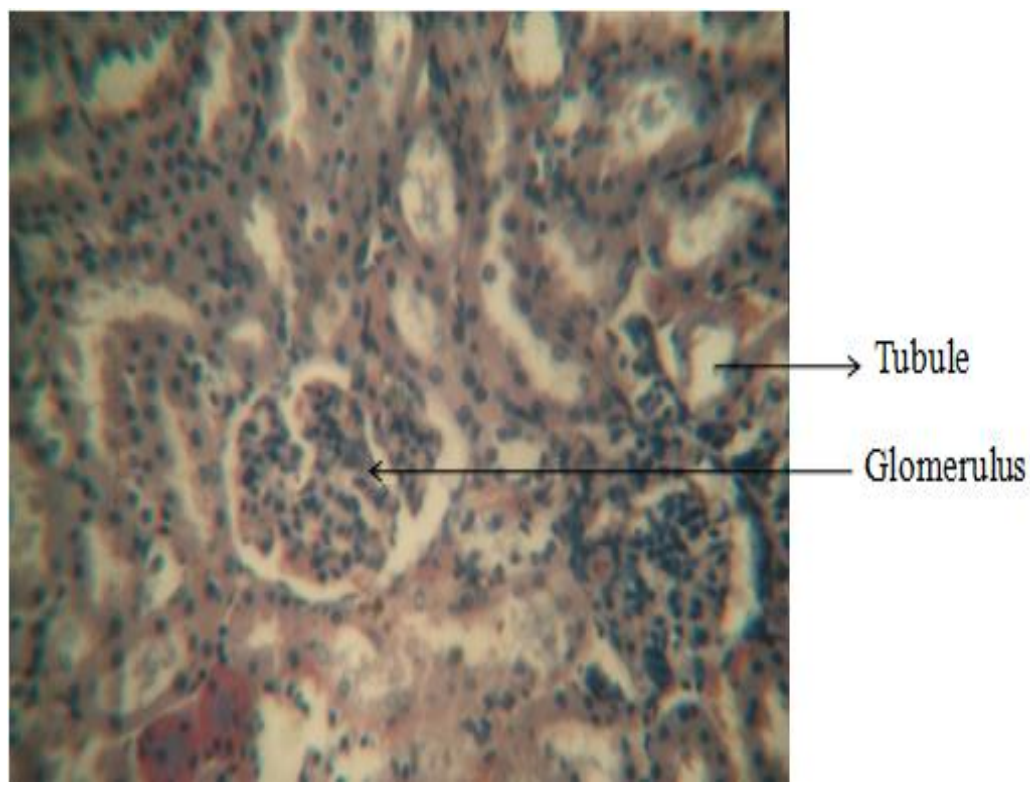

Plate 4 (Paraquate intoxication, $+400 \mathrm{mg} / \mathrm{ml}$ guava extract treatment)

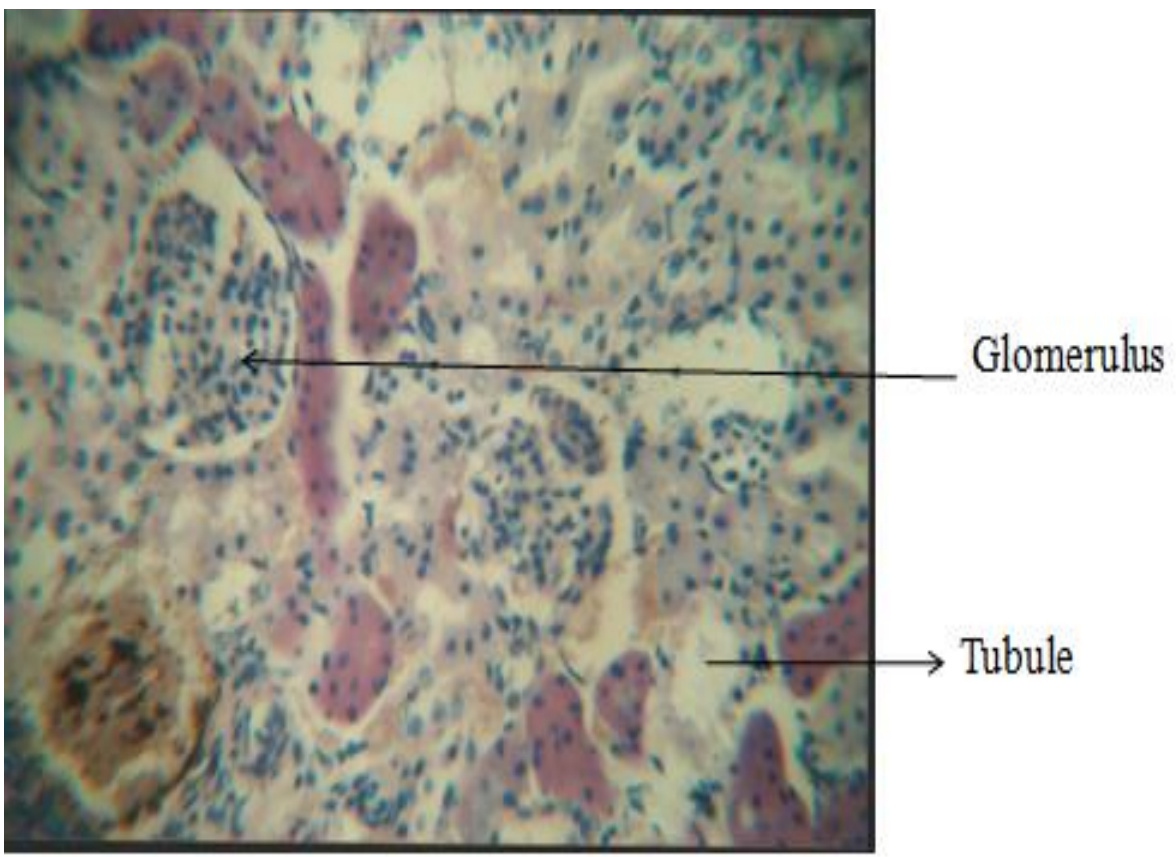

\section{Plate 5 (Paraquate intoxication, $+800 \mathrm{mg} / \mathrm{ml}$ guava extract treatment)}

The dose of $3.5 \mathrm{mg} / \mathrm{kg}$ b.wt of paraquat was chosen to induce toxicity and oxidative stress based on the dose optimization of paraquat according to Shanker et al 2011. They recorded severe signs of toxicity, and $80 \%$ mortality when $10 \mathrm{mg} / \mathrm{kg}$ b.wt of PQ was used for intoxication and $60 \%$ and $30 \%$ mortality when $7.0 \mathrm{mg} / \mathrm{kg}$ b.wt and $3.5 \mathrm{mg} / \mathrm{kg}$ b.wt of PQ were used respectively, hence the need to choose the lesser toxic dose of $3.5 \mathrm{mg} / \mathrm{kg}$ b.wt.

The result of the kidney parameters showed a significant increase of serum creatinine, serum urea, sodium concentrations and a non significant variation of chloride concentration at $(\mathrm{p}<0.05)$. There was also a significant decrease of potassium concentration in the paraquat group after paraquat exposure at $(\mathrm{p}<0.05)$. Creatinine is a non protein waste product of creatine phosphate metabolism and can be used to evaluate renal dysfunction. Renal dysfunction diminishes the ability to filter creatinine and serum creatinine rises. Creatinine is useful as a long term marker of renal function. In this study, there was a significant increase of serum creatinine 
concentration in the paraquat group at $(\mathrm{p}<0.05)$ after paraquat exposure, which corresponded with the findings of Hawazen and Maisaa, 2009 that paraquat induced many histological alterations in the kidney of albino rats exposed to them such as increased creatinine concentration. This could probably be attributed to the renal dysfunction caused by paraquat in the kidney.

Urea which is synthesized by the liver is a good marker of acute renal disease . In this study, there was a significant increase of serum urea in the paraquat group at $(\mathrm{p}<0.05)$ probably as a result of the damage inferred on the kidney by paraquat intoxication. As an excretory product, it is not supposed to be retained in the blood, but an increased concentration was seen which suggests renal dysfunction. Administration of P. Guajava leaf ethanol extract was able to bring down the elevated concentration of serum urea to normal as seen in the treated groups. This equally showed that P.guajava restored significantly the renal function.

Electrolytes are ions in solution which acquire the capacity to conduct electricity and their balance in the body of an organism is essential for the normal functioning of cells and organs. According to Gabriel et al 2009, the basic function of electrolytes in the body lies in the control of fluid distribution, intracellular and extracellular acido-basic equilibrium which culminates in the proper maintenance of osmotic pressure of the body fluids and normal neuro-muscular irritability. Sodium ion is the major cation in the extracellular fluid. It plays a critical role in the body functions. The brain, nervous system and muscle requires the transmission of electrical signals for the organism's communication. Chloride is the major anion found outside of the cell and blood. It combines with sodium in the body to form sodium chloride $(\mathrm{NaCl})$ and plays the role of helping the body to maintain normal fluid balance Gabriel et al 2009. Potassium is found mainly inside the body's cell.

In this present study, there was a significant increase of sodium ion concentration and a non significant increase of chloride ion concentration at $(\mathrm{p}<0.05)$. There was also a significant decrease of potassium ion concentration seen in the paraquat group after paraquat intoxication at $(\mathrm{p}<0.05)$ which corresponds with the findings of Edori et al 2013 which says that paraquat can cause marked changes in electrolyte concentrations of fish. The implication of the over production and under production of these electrolytes can lead to cell malfunctioning and also indicates damage to the kidney Rajanna et al 1981. The marked changes observed in the electrolytes of these rats after paraquat exposure might be as a result of the deleterious effects caused by paraquat. Treatment with PG leaf ethanol extract was seen to be able to ameliorate these marked changes in the electrolyte concentrations and proper maintenance of osmotic pressure of the body fluids and normal neuro-muscular irritability were restored.

Neutrophils are the most abundant type of white blood cells and the most abundant type of granulocytes in most mammals. They form an essential part of innate system. They are often one of the first responders of inflammatory cells to migrate towards the site of inflammation, in acute phase of inflammation, particularly as a result of bacterial infection. Jacobs et al 2010.

Lymphocytes are type of white blood cells, part of the immune system. Increase in Lymphocytes usually occurs as a result of virus, toxins and pathogen invasion. In this study, treatment with PG significantly $(\mathrm{p}<0.05)$ reversed the reduction in Neutrophil and improved platelet count. Also the WBC-T was seen to be reduced to normal after treatment with PG. This implies that the anomaly caused by paraquat induction in the blood were significantly restored.

The result of the reproductive hormone showed a significant decrease of testosterone concentration, FSH, and non-significant decrease of LH and prolactin at $(\mathrm{p}<0.05)$.

FSH is a glycoprotein polypeptide hormone which regulates the development, pubertal maturation and reproductive processes of the body. Diminished secretion of FSH can result in failure of gonadal function. Luteinizing hormone is produced by the gonadotrophic cells in the anterior pituitary gland. It triggers ovulation and development of corpus lutem in females and stimulates leydig cell production of testosterone in males. Testosterone is a steroid hormone secreted primarily by the testes of male and to a lesser extent the ovaries of female. It initiates the development of male internal and external reproductive organs during foetal development and is essential for the production of sperm in adult life. Testosterone ensures that muscles and bones stay strong during and after puberty and enhances libido both in men and women. LH and FSH are two important messenger hormones made by the pituitary gland that act on the testes. In this study, there was a significant decrease of testosterone concentration, FSH and a non-significant decrease of LH and prolactin at which corresponded with the findings of Zain.A 2007 that paraquat significantly decreased the concentrations of testosterone, FSH, LH and prolactin of rats exposed to it. They were affected by paraquat through oxidative stress mechanism. The cells, tissues and organs necessary for the production of these hormones were affected which brought about low secretion of hormones compared to the normal. The PG extract through antioxidant mechanism, restored the hormonal concentrations and functions.

www.scirj.org 
In conclusion, accidental deaths and suicides from paraquat ingestion are relatively common. A large majority (93 percent) of fatalities from paraquat poisoning are suicides, which occur mostly in developing countries (Dinham 1996), Psidium guajava due to its local availability and its antioxidant properties could be recommended in the treatment of paraquat poisoning arising from occupational exposure, suicide or accidents to children.

\section{References:}

Castello, P.R., Drechsel, D.A, and Pate, M. (2007). Mitochondria are a major source of paraquat-induced reactive oxygen species production in the brain. Journal of Biological Chemistry, 282, 14186-14193.

Cocheme, H,M, and Murphy, M.P (2009). The uptake and interaction of the redox cycler paraquat with mitochondrial. Methods in enzymology, 456, 395-417

Dinham,B.(1996). Active ingredients fact sheet, paraquat pesticide news 32, 20-21.

Edori, O.S., Edori, E.S, and Okpara, K.E. (2013). Chronic toxicity of paraquat on liver and $\quad$ gill electrolyte in the Catfish ClariasGariepinus. Journal of environmental science, $\quad$ toxicology \& food technology, 7(4), 1-4

Fabiny, D.L and Ertingshausen, G. (1971). Automated reaction-rate method for determination $\quad$ of $\quad$ serum Creatinine with centrifichem. Clinical Chemistry, 17, 696-700.

Gabriel, U.U., Jack, I.R., Edori, O.S, and Ejobueze, E. (2009). Electrolytes in selected tissues $\quad$ of $\quad$ Heterobranchus Bidorasalis treated with sublethal levels cypermethrin. Ethiopian journal of environmental studies and management, 2(3), 83-87.

Hawazen, A.L, and Maisaa, M. (2009). Effect of Antrox on paraquat -induced histological and biochemical changes in kidney of Albino Rats. Journal of applied sciences research, 3(10), 988-993.

Jacobs, L., Nawrot, T.S., Degeus, B., Meeusen, R., Degraeuwe, B., Bernard, A., Sughis, M., $\quad$ Nemery, B, and Panis, L. (2010). Subclinical responses in healthy cyclist briefly exposed to traffic-related air pollution: An intervention study. Journal of environmental health, 9(1), 64

Joseph, B and Priya, M (2011). Review on nutritional, medicinal and pharmacological properties of guava (Psidium guajava Linn) International Journal of Pharmarceutical and Biological Sciences, 2, 53-69.

Manosroi, J., Dhumtanom, P, and Manosroi, A. (2006). Anti-proliferative activity of essential oil extracted from Thai medicinal plants on KB and P388 cell lines. Cancer Letters, $\quad$ 235, 114-120.

Maruna RFL,(1958). Colometric determination of sodium in human serum and plasma. Clinical Chemistry Acta, 2, 581

Odell,W.D, and Parlow, A.F. (1981). Follicle Stimulating Hormone test system. Journal of

Clinical Investigation 47,2551.

Samistha, D, and Swarnamoni, D. (2010). A study of the anti-inflammatory effect of the leaves of psidium guajava Linn.on experimental animal models. Pharmacognosy Research,2(5), 313-317.

Searcy, R.L., Reardon, J.E, and Foreman, J.A. (1967). A new photometric method for serum, $\quad$ urea, $\quad$ nitrogen determination. American Journal of Medicine. 33(1), 15-20

Shanker, K.S., Umesh, D., Meena, K, and Priyambada, K. (2011). Ameliorative Activity of

Withania Somnifera Root Extract on paraquat induced oxidative stress in mice. Journal of Pharmacology and Toxicology, 6, 433-439.

Skeggs, L.T, and Hochstrasser, H.C. (1964). Comparative study of Plasma Electrolytes. Clinical Chemistry, $10,918$.

Suntress, Z.E. (2002). Role of antioxidants in paraquat toxicity. Toxicology journal, 168, 65-77

Terri, A.E, and Sessin, P.G. (1958). Pariksha Neochem Potassium kit. American journal of

Clinical Pathology, 29: 86

www.scirj.org

(C) 2019, Scientific Research Journal

http://dx.doi.org/10.31364/SCIRJ/v7.i4.2019.P0419633 
Tietz,N.W. (1995): Clinical giude to Laboratory test. 3rd ed.Philadelphia. W.A. Sauders Co.

Trinder, P, (1951). A rapid method for the determination of sodium in serum. Analyst, 76,

596.

Wennick, J.M., Delemaarre, H.A., Schoemaker, R., Schoemaker,H, and Schoemaker, J. (1990). Lutenizing hormone and follicle stimulating hormone secretion patterns in girls throughout puberty measured using highly sensitive immunoradiometric assays. ClinicalEndocrinology, (OFX) 33, 333-344.

Zain, A (2007). The evaluation of the toxic effect of paraquat and its mechanism of action on Thesis: University Sains Malaysia.

reproductive system of male rats. 